\title{
Computação e Eu: Uma Proposta de Educação em Computação para o Sexto Ano do Ensino Fundamental II
}

\author{
Bianca L. Santana ${ }^{1}$, Luis Gustavo J. Araújo ${ }^{1}$, Roberto A. Bittencourt ${ }^{1}$ \\ ${ }^{1}$ UEFS - Universidade Estadual de Feira de Santana \\ Av. Transnordestina, s/n, Novo Horizonte \\ Feira de Santana - BA, Brasil - 44036-900 \\ \{biancasantana.ls, luisaraujo.ifba\}@gmail.com, roberto@uefs.br
}

\begin{abstract}
Computing skills are increasingly needed in contemporary life. This makes educators consider teaching computing from the initial grades of basic education. However, in addition to the need of defining reference curricula, our community needs to develop materials appropriate to the age of these students and to the Brazilian reality. This paper describes a proposal of a computing textbook for the sixth year of Brazilian middle school that seeks to integrate fundamental concepts of computer science, domain of technologies and computational thinking skills. Part of the developed materials were preliminarily used with sixth-grade students from a state public school. Results suggest that the book has proven appropriate to the target audience, ensuring students' immersion in the world of information technology.
\end{abstract}

Resumo. Habilidades relacionadas à computação são cada vez mais necessárias à vida contemporânea. Isto faz com que educadores considerem o ensino de computação desde as séries iniciais da educação básica. Para tanto, além da necessidade de definir referenciais curriculares, é preciso desenvolver materiais didáticos apropriados à idade destes estudantes e à realidade brasileira. Este artigo descreve uma proposta de um livro didático de computação para o sexto ano do Ensino Fundamental II, que busca integrar conceitos fundamentais da ciência da computação, domínio de tecnologias e habilidades de pensamento computacional. Parte dos materiais desenvolvidos foram aplicados preliminarmente com estudantes do sexto ano de uma escola pública estadual. Os resultados sugerem que o livro mostrou-se adequado ao público-alvo, garantindo a imersão dos estudantes no mundo da tecnologia da informação.

\section{Introdução}

A vida contemporânea demanda de todos o domínio de habilidades de computação, o que leva à inserção da computação nos currículos escolares [CSTA and ACM 2016]. No Brasil, a comunidade acadêmica é prolífica em trabalhos sobre a computação na educação básica [Santos et al. 2018]. Para acelerar a inserção da computação nas escolas brasileiras, a Sociedade Brasileira de Computação criou, em 2017, os Referenciais de Formação em Computação: Educação Básica [SBC 2017]. Por outro lado, para haver sucesso nessas iniciativas, é preciso contar com material didático em português adequado e planejado com base em referenciais curriculares e em experiências bem-sucedidas. Há muitos livros e materiais didáticos em língua inglesa, mas a comunidade brasileira ainda se ressente da 
falta de materiais didáticos de computação na educação básica. E mesmo os materiais didáticos desenvolvidos [Santos et al. 2018] não costuma aderir explicitamente a referenciais curriculares. Esta necessidade colocou os autores deste trabalho numa direção da construção de um currículo para o Ensino Fundamental II brasileiro, do sexto ao nono anos da educação básica.

Como primeiro resultado deste desafio a que nos lançamos, apresentamos neste artigo uma proposta de currículo e materiais didáticos para o sexto ano do ensino fundamental. O currículo proposto é baseado nos eixos temáticos e resultados de aprendizagem do currículo da CSTA [CSTA and ACM 2016], e o livro é baseado em atividades desplugadas e linguagens de bloco, pensamento computacional e conceitos de computação.

\section{Fundamentação Teórica}

Pensamento Computacional (PC) é um conceito importante a ser levado em consideração quando pretende-se ensinar computação a crianças. Segundo Wing, Pensamento Computacional (do inglês, Computational Thinking) "envolve resolver problemas, projetar sistemas e compreender o comportamento humano, baseando-se nos conceitos fundamentais para ciência da computação" [Wing 2006].

Por outro lado, com o avanço tecnológico e a disseminação dos saberes digitais, a Fluência Digital tornou-se importante na formação dos jovens. Esta fluência digital não se limita a apenas utilizar os dispositivos e aplicativos, mas também a criá-los [Resnick et al. 2009]. Assim, diversas iniciativas são executadas em escolas em nível local, ou implementadas na forma de currículos em nível nacional ou global.

Embora atualmente tenhamos muitas iniciativas para o ensino da computação para crianças, estas abordagens não são novas. Na década de 1970, o pesquisador e professor Seymour Papert vislumbrou a potencialidade da computação para além do mero uso do computador. Seus estudos sobre o Construcionismo, uma derivação do Construtivimo de Jean Piaget, foram ponto de partida de uma série de estudos e ferramentas para ensinar computação para crianças, tendo forte influência nas abordagens e ferramentas atuais.

Uma das primeiras experiências de computação na escola foi justamente a de Seymour Papert. O uso do Logo se tornou popular, na década de 1980, principalmente no Apple II, fazendo com que os pesquisadores do MIT focassem em pesquisas utilizando o screen turtle [McNerney 2004].

Diversos países têm adotado currículos de Computação para as escolas. Nos Estados Unidos, frameworks como o CSTA e o "AP Computer Science Principles Course and Exam Description" são exemplos de documentos que fornecem uma base para apoiar a Computação nas escolas [CSTA and ACM 2016, The College Board 2017]. Em Israel, desde a década de 1990, existe um modelo curricular para computação nas escolas [Hazzan et al. 2008]. Segundo o relatório da Royal Society, países como Reino Unido, Nova Zelândia, Alemanha, Índia e A Coreia do Sul também introduziram a computação em suas escolas [Royal Society 2012].

No Brasil, diversos pesquisadores e instituições têm seguido a tendência mundial, propondo currículos para a Computação na Educação Básica. Em 2017, a Sociedade Brasileira de Computação (SBC) criou referenciais curriculares de computação para a Educação Básica [SBC 2017]. Além destes referenciais, outras instituições têm proposto 
currículos específicos, como o Currículo de Tecnologia e Computação da Educação Infantil ao Ensino Fundamental, dividido em três eixos: Pensamento Computacional, Cultura Digital e Tecnologia Digital [CIEB 2018].

Além desses currículos, diversos materiais didáticos foram produzidos para crianças ao longo da história da Computação nas escolas. Os livros de Seymour Papert e Cynthia Solomon, Twenty Things To Do With a Computer [Papert and Solomon 1971] e Tim Bell, CS Unplugged [Bell et al. 1998] são marcos importantes. No mesmo sentido, diversos pesquisadores e professores têm criado e aperfeiçoado materiais didáticos para o ensino da computação como Computacional.com, Programa.Aê e Ciencia De La Computación Para el Aula.

\section{Computação e Eu: Uma Proposta para o $6^{\circ}$ ano}

Neste trabalho, elaboramos o currículo para o $6^{\circ}$ ano do ensino fundamental, bem como o planejamento das aulas e materiais necessários para a execução deste currículo. Esta é a primeira etapa de um objetivo maior, que é propor um currículo de Educação em Computação para o Ensino Fundamental II, do $6^{\circ}$ ao $9^{\circ}$ anos.

O programa do $6^{\circ}$ ano busca que os estudantes desta série escolar conheçam alguns conceitos centrais da Ciência da Computação. Também é um macro-objetivo deste programa integrar habilidades básicas em tecnologia com conceitos básicos sobre Pensamento Computacional. As experiências de aprendizagem propostas em cada aula foram projetadas para que os estudantes percebam a computação como uma parte importante de seu mundo.

No currículo desta série, os resultados de aprendizagem gerais estão definidos em torno de quatro eixos centrais: Pensamento Computacional; Colaboração; Práticas de Computação e Programação; e Computadores e Dispositivos de Comunicação. Cada um dos eixos possui uma série de tópicos que devem ser cumpridos. Estes tópicos foram selecionados a partir dos cinco eixos do CSTA K-12 Computer Science Standards, sendo que o eixo adicional sobre Impactos Comunitários, Globais e Éticos foi deslocado para séries posteriores [Seehorn et al. 2011]. A Figura 1 lista estes tópicos.

O Pensamento Computacional trata de um conjunto de habilidades que podem ser utilizadas para analisar e desenvolver soluções para problemas que podem ser resolvidos computacionalmente. Colaboração parte da ideia de que a Ciência da Computação é uma disciplina intrinsecamente colaborativa e, neste sentido, os estudantes participam de atividades colaborativas de solução de problemas. As Práticas de Computação e Programação são pautadas principalmente no uso de ferramentas computacionais, incluindo a exploração do uso de programação na resolução de problemas. Computadores e Dispositivos de Comunicação é um eixo pensado para que os estudantes entendam os elementos dos computadores e dispositivos de comunicação modernos, além de serem apresentados a dispositivos e mídias que podem auxiliá-los em suas atividades de aprendizagem.

\subsection{Proposta de ensino-aprendizagem para $06^{\circ}$ ano}

Nossa abordagem para o $6^{\circ}$ ano foi planejada para um mínimo de 60 horas-aula, com duas horas-aula semanais, que ocorrem conjugadas. Elaboramos 30 aulas no total, divididas em quatro unidades de aprendizagem. As aulas que fazem uso do computador devem ocorrer 
PC1. Usar recursos tecnológicos para resolver problemas adequados. PC2. Usar ferramentas de escrita, câmeras digitais e ferramentas de desenho para ilustrar pensamentos, ideias e histórias com passo-a-passo.

PC3. Entender como classificar informações sem usar um computador.

PC4. Reconhecer que o software é criado para controlar as operações do computador.

PC5. Demonstrar como 0s e 1s podem ser usados para representar informações.

PC6. Entender e utilizar as etapas básicas na resolução algorítmica de problemas.

PC7. Desenvolver um entendimento simples de um algoritmo usando exercícios sem computador.

PC8. Demonstrar como uma sequência de bits pode ser usada para representar informações alfanuméricas.

PC9. Fazer uma lista de subproblemas a considerar ao abordar um problema maior.

PC10. Compreender as conexões entre ciência da computação e outros campos.
PCC1. Usar recursos tecnológicos para realizar pesquisas apropriadas.

PCC2. Criar produtos multimídia com o apoio de professores, membros da família ou parceiros estudantis.

PCC3. Construir um conjunto de instruções para realizar uma tarefa simples.

PCC4. Identificar trabalhos que usam computação e tecnologia.

PCC5. Usar ferramentas de tecnologia para atividades de redação, comunicação e publicação individuais.

PCC6. Construir um programa como um conjunto de instruções passo-a-passo para ser encenado.

PCC7. Implementar soluções de problemas usando uma linguagem de programação visual baseada em blocos.

PCC8. Navegar entre páginas da Web usando hiperlinks e conduzir pesquisas simples usando mecanismos de pesquisa.

PCC9. Identificar uma ampla gama de trabalhos que exigem conhecimento ou uso de computação.

\begin{tabular}{|c|c|}
\hline Pensamento Computacional & $\begin{array}{l}\text { ação } \begin{array}{l}\text { Prática de computação e } \\
\text { programação }\end{array} \\
\begin{array}{l}\text { Computadores e Dispositivos } \\
\text { de Comunicação }\end{array}\end{array}$ \\
\hline $\begin{array}{l}\text { C1. Trabalhar de forma cooperativa e colaborativa com colegas, } \\
\text { professores e outros que usam tecnologia. } \\
\text { C2. Usar ferramentas de tecnologia de produtividade. } \\
\text { C3. Identificar maneiras pelas quais o trabalho em equipe e a } \\
\text { colaboração podem apoiar a solução de problemas e a inovação. }\end{array}$ & $\begin{array}{l}\text { CDC1. Demonstrar um nível apropriado de proficiência na utilização } \\
\text { de dispositivos de entrada e saída padrão, para operar com } \\
\text { sucesso computadores e tecnologias relacionadas. } \\
\text { CDC2. Compreender a difusão dos computadores e computação na } \\
\text { vida diária. } \\
\text { CDC3. Aplicar estratégias para identificar problemas simples de } \\
\text { hardware e software que possam ocorrer durante o uso. } \\
\text { CDC4. Identifique os fatores que distinguem os seres humanos das } \\
\text { máquinas. }\end{array}$ \\
\hline
\end{tabular}

Figura 1. Resultados de Aprendizagem para o $6^{\circ}$ ano.

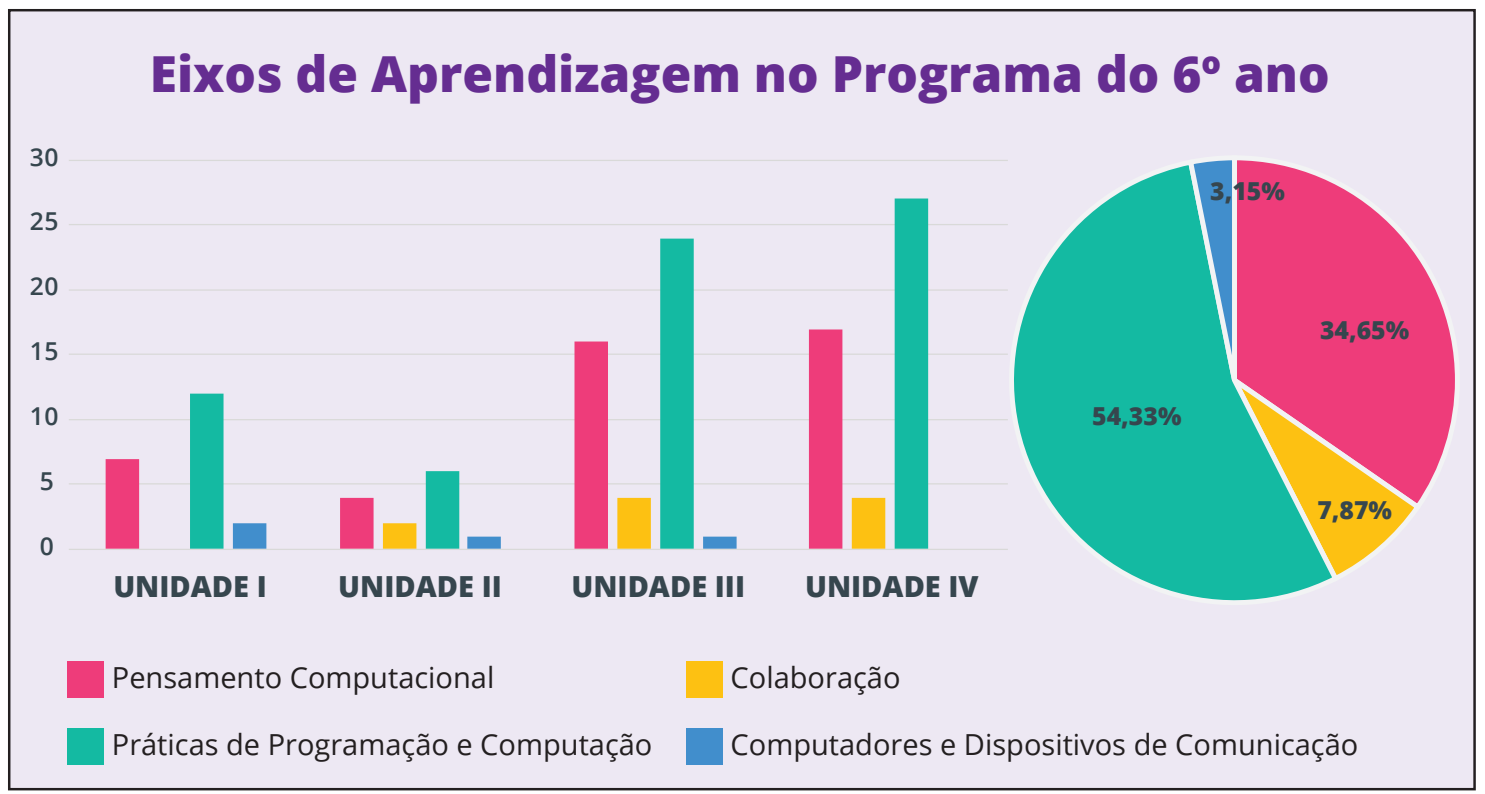

Figura 2. Distribuição dos Resultados de Aprendizagem ao longo do ano. 
em laboratório, contendo de preferência uma máquina por estudante. Nossa abordagem também prevê um professor com conhecimentos básicos na área, incluindo noções de algoritmos, programação em linguagens de blocos e conceitos básicos de computação.

A Figura 3 lista as aulas em cada unidade, bem como os resultados de aprendizagem esperados e os conteúdos. A Unidade I tem como objetivo promover uma introdução branda ao universo da Computação. Nas primeiras aulas, os estudantes conhecem a representação binária, as definições de computador e seu funcionamento básico. Estes conteúdos são trabalhados através de dinâmicas de computação desplugada, jogos de tabuleiro, e exercícios escritos. A segunda parte desta unidade é dedicada à introdução à programação através da criação de algoritmos em dinâmicas desplugadas e tutoriais selecionados da iniciativa Code.org.

$\mathrm{Na}$ Unidade II, as noções de informática básica são aprofundadas com atividades para melhoria do controle de mouse e teclado e o uso de ferramentas de desenho, edição de texto e imagens. Também são tratados conceitos de computação como álgebra booleana $\mathrm{e}$ compressão de texto, abordados com baixa complexidade a fim de considerar o nível dos estudantes. Também propomos uma natureza diversa de atividades para serem realizadas em sala de aula, com desafios para realização de atividades no computador, atividades escritas e dinâmicas de computação desplugada.

As Unidades III e IV têm como tema principal a introdução à programação com Scratch. As aulas destas unidades foram inspiradas nas propostas do livro Creative Computing [Brennan 2013]. Durante as aulas, os estudantes são incentivados a se expressarem artisticamente através da criação de animações. Ao mesmo passo em que vivenciam a experiência de utilizar o computador como meio de expressão artística, conceitos de programação de computadores e PC são trabalhados em sala de aula. Os projetos solicitados ficam mais complexos a cada aula. Para propor experiências de aprendizagem ricas, as lições combinam dinâmicas de computação desplugada, desafios de programação e depuração de código, dentre outros.

Os resultados de aprendizagem esperados são trabalhados ao longo do ano letivo, de maneira que cada aula aborda um ou mais tópicos. A Figura 2 apresenta dois gráficos, um com a distribuição dos tópicos de cada eixo de aprendizagem entre as unidades, o outro com a porcentagem com que cada eixo é trabalhado ao longo do ano. Pensamento Computacional e Práticas de Programação e Computação são os eixos mais trabalhados, recebendo muita ênfase nas Unidades III e IV. Embora as Práticas de Programação e Computação apareçam com mais frequência que os tópicos de Pensamento Computacional, esses dois eixos são trabalhados de maneira concomitante. O eixo Computadores e Dispositivos de Comunicação é o menos trabalhado e aparece nas primeiras unidades, pois estas possuem mais lições envolvendo o uso do computador em si. A medida que aumenta a complexidade dos trabalhos, a colaboração entre colegas torna-se importante, especialmente após a Unidade I.

\subsection{Estrutura do Livro}

O livro Computação e $E u^{1}$ possui duas versões, uma voltada para professores e outra que pode ser distribuída entre os alunos. O livro do professor possui diretrizes, instruções

\footnotetext{
${ }^{1}$ Disponível em https://sites.google.com/view/computacaofundamental/
} 
gerais e materiais a serem utilizados em sala, enquanto o livro do aluno é uma compilação das atividades escritas a serem realizadas em aula e como tarefa para casa.

A versão para professores oferece um guia completo para professores que ministrarão a disciplina. O capítulo inicial é dedicado à apresentação da proposta e dos eixos que norteiam a nossa abordagem para o $6^{\circ}$ ano do ensino fundamental II. No capítulo 2 , apresentamos as aulas e seus respectivos conteúdos de maneira resumida. O restante do livro é dedicado à descrição detalhada das aulas e dos materiais necessários.

As aulas estão organizadas de acordo com a sequência apresentada na Figura 3. Cada aula é descrita através de um plano de aula detalhado, que serve para orientar e organizar o trabalho do professor. Cada plano possui em sua primeira página:

- Sumário: Resumo do tema da aula;

- Objetivos: Lista de habilidades que serão desenvolvidas no decorrer da aula;

- Conteúdo: Lista de conteúdos que serão trabalhados durante a aula;

- Atividades: Lista das atividades realizadas durante a aula e como tarefa para casa;

- Resultados de Aprendizagem: Lista de resultados de aprendizagem esperados para a aula, considerando os eixos de aprendizagem que norteiam a proposta;

- Materiais: Lista de materiais para a aula, incluindo links para materiais externos.

A partir da segunda página, descrevemos o desenvolvimento da aula, que é o passo a passo de como as atividades serão desenvolvidas e como as estratégias didáticas serão utilizadas (e.g., slides, dinâmicas desplugadas, jogos, músicas, figuras).

As aulas que possuem uma carga maior de novos conteúdos possuem uma seção intitulada Tópicos Relevantes. Esta página descreve brevemente alguns dos conceitos empregados na aula e deve apoiar os estudantes durante a execução de suas tarefas. As aulas que possuem atividades de escrita ou que necessitam de um guia para as atividades possuem uma seção intitulada Folha de Tarefas. Algumas aulas também possuem uma seção intitulada Tarefa para Casa, reservada para as atividades extra-classe. Todas estas seções, quando existem, também estão presentes na versão do livro para estudantes.

Nossa proposta de disciplina não prevê atividades avaliativas, embora os professores sejam livres para avaliar os estudantes em avaliações somativas através das atividades propostas. Em termos de avaliação continuada, os estudantes devem ser estimulados a escrever um diário de bordo após cada aula. A versão do estudante possui espaço reservado para o diário de bordo. Os professores podem usar estes diários para compreender como os estudantes entenderam a proposta da aula, o que eles consideram que aprenderam, quais as facilidades e dificuldades enfrentadas e demais reflexões. Os professores devem usar estes diários como mediação para aprimoramento das estratégias empregadas, buscando aumentar o engajamento dos estudantes no processo de ensino-aprendizagem.

Adicionalmente, algumas aulas fazem uso das propostas do livro Computer Science Unplugged [Bell et al. 1998, Bell et al. 2009], possuindo, na lista de materiais, as referências das atividades empregadas. Materiais impressos para algumas das dinâmicas desplugadas, além de mídias e programas-base para os trabalhos no computador, são disponibilizados em um site de apoio.

\section{Experiência Preliminar}

Nesta seção, apresentamos o cenário, participantes e atividades desenvolvidas através da aplicação do material do livro Computação e Eu. 


\begin{tabular}{|c|c|c|}
\hline & AULA & CONTEÚDO \\
\hline \multirow{8}{*}{ 분 } & $\begin{array}{l}1 \text { Números Binários } \\
\text { PC5, PC8 e CDC2 }\end{array}$ & $\begin{array}{l}\text { Definição formal do Computador; } \\
\text { Números binários e decimais: representação e conversão; } \\
\text { Representação de caracteres alfanuméricos. }\end{array}$ \\
\hline & $\begin{array}{l}2 \text { Arquivos Digitais } \\
\text { PC4 }\end{array}$ & $\begin{array}{l}\text { Imagem Digital: Pixel e Matrizes de pixel; } \\
\text { Números Binários. }\end{array}$ \\
\hline & $\begin{array}{l}3 \text { Hardware e suas Funções } \\
\text { CDC1 }\end{array}$ & $\begin{array}{l}\text { Hardware: Entrada, Saída, Processamento } \\
\text { e Armazenamento. }\end{array}$ \\
\hline & $\begin{array}{l}4 \begin{array}{l}\text { Resolvendo Problemas do Computador } \\
\text { CDC3 }\end{array} \\
\end{array}$ & $\begin{array}{l}\text { Problemas de hardware e problema de software; } \\
\text { Ações básicas no uso do Computador. }\end{array}$ \\
\hline & $\begin{array}{l}5 \text { Algoritmos e Programação em Blocos (Sequências) } \\
\text { PC6, PCC } 3, P C C 6 \text { e PCC }\end{array}$ & $\begin{array}{l}\text { Algoritmos em sequência; } \\
\text { Programas em sequência em uma linguagem de blocos; } \\
\text { Fluxo de execução de um programa. }\end{array}$ \\
\hline & $\begin{array}{l}6 \text { Algoritmos e Programação em Blocos (Loops) } \\
\text { PC6, PCC 3, PCC6 e PCC7 }\end{array}$ & $\begin{array}{l}\text { Algoritmos com loops; } \\
\text { Programas com loops em uma linguagem de blocos. }\end{array}$ \\
\hline & $\begin{array}{l}7 \text { Algoritmos e Programação em Blocos (Depuração) } \\
\text { PC6, PCC 3, PCC6, e PCC7 }\end{array}$ & $\begin{array}{l}\text { Algoritmos com loops; } \\
\text { Programas com loops em uma linguagem de blocos; } \\
\text { Identificação e correção de bugs. }\end{array}$ \\
\hline & $\begin{array}{l}8 \text { Algoritmos e Programação em Blocos (Condições) } \\
\text { PC6, PCC3, PCC6 e PCC7 }\end{array}$ & $\begin{array}{l}\text { Algoritmos com condições; } \\
\text { Programas com condições em uma linguagem de blocos. }\end{array}$ \\
\hline \multirow{7}{*}{ 至 } & $\begin{array}{l}1 \text { Desenhando no Computador } \\
P C C 2 \text { e } C D C 1\end{array}$ & $\begin{array}{l}\text { Controle do Mouse; } \\
\text { Edição de Imagens; } \\
\text { Funções Básicas do Menu. }\end{array}$ \\
\hline & $\begin{array}{l}2 \text { O Jogo da Digitação } \\
P C C 5, C D C 1 \text { e } C D C 3\end{array}$ & $\begin{array}{l}\text { Organização dos caracteres do teclado; } \\
\text { Digitação de texto. }\end{array}$ \\
\hline & $\begin{array}{ll}3 & \text { Busca na Web } \\
\text { PC1, } & \text { PCC1 e PCC8 }\end{array}$ & $\begin{array}{l}\text { Busca da Web; } \\
\text { Digitação de texto. }\end{array}$ \\
\hline & $\begin{array}{l}4 \text { Edição de Texto - PARTE } 1 \\
C 2, \text { PCC5 e CDC1 }\end{array}$ & $\begin{array}{l}\text { Edição de texto; } \\
\text { Função básica dos editores de texto. }\end{array}$ \\
\hline & $\begin{array}{l}5 \text { Edição de Texto - PARTE } 2 \\
C 2, P C C 5 \text { e } C D C 1\end{array}$ & $\begin{array}{l}\text { Edição de texto e imagens; } \\
\text { Funcionalidades básicas dos editores de texto. }\end{array}$ \\
\hline & $\begin{array}{l}6 \text { Portas Lógicas } \\
\text { PC5 e PC10 }\end{array}$ & Álgebra booleana: verdadeiro, falso, E, OU e NÃO. \\
\hline & $\begin{array}{l}\text { Compressão de Texto } \\
\text { PC10 }\end{array}$ & $\begin{array}{l}\text { Reconhecimento de Padrões; } \\
\text { Memória do Computador. }\end{array}$ \\
\hline \multirow{8}{*}{$\begin{array}{l}\text { 를 } \\
\text { 늠 } \\
\text { 은 }\end{array}$} & $\begin{array}{l}\text { Introdução ao Scratch } \\
\text { PC2, PC4, PCC4 e PCC9 }\end{array}$ & Scratch. \\
\hline & \begin{tabular}{|l}
2 Programado para dançar \\
$\mathrm{PC} 4, \mathrm{PC} 7, \mathrm{C} 1, \mathrm{C} 3, \mathrm{PCC} 3$ e CDC4
\end{tabular} & Algoritmo (Sequência). \\
\hline & $\begin{array}{ll}3 & \text { Desafio dos Blocos } \\
\text { PC4, PCC2, PCC 3, PCC6 e PCC7 }\end{array}$ & $\begin{array}{l}\text { Sequência de execução de um programa; } \\
\text { Comandos de movimento, aparência, controle e eventos. }\end{array}$ \\
\hline & $\begin{array}{l}4 \text { Debugar! } \\
\text { PC6, PC9, C1, C3 e PCC6 }\end{array}$ & Depuração de código. \\
\hline & $\begin{array}{l}5 \text { O que eu quero ser no futuro... } \\
P C 2, P C C 2, P C C 5 \text { e } P C C 6\end{array}$ & $\begin{array}{l}\text { Sequência de execução de um programa; } \\
\text { Comandos de movimento, aparência, controle e eventos. }\end{array}$ \\
\hline & \begin{tabular}{|l}
6 Construindo uma banda \\
PC4, PC6, PCC2, PCC $3, P C C 5$ e $P C C 7$ \\
\end{tabular} & $\begin{array}{l}\text { Algoritmos (Paralelismo); } \\
\text { Comandos de movimento, aparência, controle e eventos. }\end{array}$ \\
\hline & \begin{tabular}{|l}
7 Quadrado laranja e círculo roxo \\
PC2, PC4, PCC2, PCC 3, PCC5, PCC6 e PCC7 \\
\end{tabular} & $\begin{array}{l}\text { Comandos de movimento, aparência, controle e eventos; } \\
\text { Editor de imagens do Scratch. }\end{array}$ \\
\hline & \begin{tabular}{|l}
8 Está vivo! \\
$P C 2, P C 4, P C 6, P C 10, P C C 2, P C C 3, P C C 5, P C C 6$ e $P C C 7$
\end{tabular} & $\begin{array}{l}\text { Cenários e fantasias de atores no Scratch; } \\
\text { Comandos de aparência e controle. }\end{array}$ \\
\hline \multirow{7}{*}{$\begin{array}{l}z \\
\frac{2}{2} \\
\frac{2}{2} \\
\frac{2}{2}\end{array}$} & $\begin{array}{ll}1 & \text { Debugar! } \\
\text { PC6, PC9, C1, C3 e PCC6 } \\
\end{array}$ & Depuração de código. \\
\hline & \begin{tabular}{|l}
2 Telefone sem fio \\
$P C 2, P C C 2, P C C 3, P C C 5, P C C 6$ e $P C C 7$
\end{tabular} & $\begin{array}{l}\text { Paralelismo; } \\
\text { Comandos de aparência. }\end{array}$ \\
\hline & $\begin{array}{l}3 \text { O mais leve e o mais pesado } \\
P C 3, P C 7, P C 9, C 3 \mathrm{e} C 1\end{array}$ & Métodos de Ordenação. \\
\hline & $\begin{array}{l}4 \text { Lendas do folclore! } \\
\text { PC2, PC6, PC10, PCC2, PCC3, PCC5, PCC6, PCC7 e PCC8 }\end{array}$ & \multirow{4}{*}{$\begin{array}{l}\text { Design de estórias; } \\
\text { Algoritmos; } \\
\text { Paralelismo; } \\
\text { Sequência de execução de um programa; } \\
\text { Comandos de movimento, aparência, sons, controle } \\
\text { e eventos. }\end{array}$} \\
\hline & $\begin{array}{l}5 \text { Videoclipe } \\
P C 2, P C 10, P C C 2, P C C 3, P C C 5, \text { PCC6 e PCC7 }\end{array}$ & \\
\hline & $\begin{array}{l}6 \text { Criando uma estória interativa - PARTE } 1 \\
\mathrm{PC} 2, \mathrm{PC} 6, \mathrm{PC} 10, \mathrm{PCC} 2, \mathrm{PCC} 3, \mathrm{PCC} 5, \mathrm{PCC6} \text { e } \mathrm{PCC} 7\end{array}$ & \\
\hline & \begin{tabular}{|l}
7 Criando uma estória interativa - PARTE 2 \\
$\mathrm{PC2}, \mathrm{PC} 6, \mathrm{PC} 10, \mathrm{PCC} 2, \mathrm{PCC} 3, \mathrm{PCC} 5, \mathrm{PCC6}$ e $\mathrm{PCC} 7$
\end{tabular} & \\
\hline
\end{tabular}

Figura 3. Organização das aulas. 


\subsection{Cenário e Participantes}

Utilizamos parte dos materiais das Unidades I e II em uma escola pública estadual, no contexto de uma disciplina de Matemática, durante 9 aulas de 50 minutos. Um total de 40 estudantes do sexto ano do ensino fundamental participaram da experiência, apoiados pelo professor da disciplina e um estudante oficineiro, aluno de Engenharia de Computação.

\subsection{Atividades}

Na primeira aula, foi realizada uma atividade sobre o computador, através de discussões com os alunos, e sobre números binários, com uma atividade desplugada. Na segunda aula, foi novamente abordado o conceito de números binários, fazendo relação com a forma de reprodução digital de uma imagem. Os alunos fizeram uma atividade desplugada sobre pixels. No terceiro dia de aula, os estudantes simularam o funcionamento do computador (entrada, saída e processamento) através de um teatro, onde cada aluno desempenhou o papel de um componente.

$\mathrm{Na}$ quarta aula, os alunos jogaram um jogo de tabuleiro idealizado para ensinar conceitos sobre defeitos do computador e ações para resolvê-los. Os defeitos eram divididos entre erros de hardware e software, e os alunos deveria responder ou utilizar cartas para apresentar uma solução. Na aula seguinte, os alunos conheceram o conceito de algoritmo e utilizaram peças físicas para percorrer caminhos utilizando blocos similares ao do Scratch. Assim como na aula anterior, na sexta, os alunos criaram algoritmos para percorrer um caminho, mas, desta vez, utilizando o conceito de loops.

No sétimo dia de aula, os alunos aprenderam o conceito de bugs, curiosidades sobre o termo e estratégias para encontrá-los, utilizando os materiais das duas aulas anteriores. No oitavo dia, os alunos desenvolveram uma atividade desplugada sobre reconhecimento de padrões em palavras, aplicando isto em compactação de informações. No último dia, os alunos realizaram uma atividade desplugada sobre comunicação.

Ao término das aulas, eram entregues atividades para casa que eram corrigidas no início da aula seguinte. Este momento servia para revisar os conteúdos, além de sanar dúvidas. Os alunos se mostraram interessados na aula e engajados, fazendo perguntas sobre temas extra-classe. Algumas atividades como a do Teatro e da compactação de informações se mostraram propensas à interdisciplinaridade. O professor de Matemática utilizou a atividade do Teatro para reforçar o conceito de potência.

\section{Discussão}

Após a nossa experiência preliminar, alguns desafios e lições aprendidas ficaram evidentes, tais como a infraestrutura, a integração no currículo, o corpo docente, dentre outros.

Infraestrutura adequada. A nossa abordagem prevê atividades com uso de diversos recursos. As dinâmicas desplugadas demandam a impressão e montagem de alguns materiais, o que envolve custos com papelaria. Algumas aulas são baseadas em explicações com uso de projeção. Além disso, parte das atividades propostas demandam um computador por aluno ou dupla. Nesse sentido, há um desafio em termos de infraestrutura, já que as aulas precisam de um ambiente com recursos diversos.

Integração no currículo. Integrar um novo componente curricular em uma estrutura de ensino já existente demanda uma série de esforços. As escolas já tem este 
desafio com outros componentes curriculares obrigatórios, uma vez que as bases curriculares proveem uma série de temas e conteúdos. Como o sexto ano do ensino fundamental já costuma contar com professores específicos para disciplinas separadas, a introdução destas atividades demanda ou a criação de disciplina específica ou a integração das aulas no contexto de outras disciplinas, como, por exemplo, matemática, ciências ou português.

Corpo docente capacitado. Como o ensino de computação é mais recente e menos aceito que outras disciplinas, não costuma haver a mesma preparação nas escolas que as outras áreas da Educação STEM (da sigla em inglês: Science, Technology, Engineering and Mathematics) possuem. Como a discussão sobre o ensino de computação nas escolas brasileiras é recente, a consequência direta é a escassez de professores capacitados para assumir uma disciplina de Computação para o ensino fundamental.

A interdisciplinaridade da computação. Entendemos que a educação em computação oferece possibilidades de interdisciplinaridade. Na experiência realizada na escola, onde o professor de matemática cedeu uma hora-aula semanal, ficou claro como a proximidade entre computação e matemática pode ser explorada para oferecer uma experiência de aprendizagem mais rica. Acreditamos que a computação pode ajudar tanto nas disciplinas mais tradicionais (e.g., matemática, história e inglês), como nos novos tópicos de ensino que se fazem necessários em uma educação para a vida contemporânea.

A computação oferece uma nova perspectiva de mundo para os estudantes. Em nossa abordagem para o sexto ano, trabalhamos com o tema da Computação e Eu, pois queremos que os estudantes entendam o computador como uma ferramenta utilizada para expressão. Eles são incentivados a expressarem seus sentimentos, seus desejos e suas preferências pessoais e artísticas enquanto aprendem sobre os temas centrais da computação. Também trabalhamos com o estudo da computação, proporcionando às pessoas a aquisição de habilidades de pensamento computacional e pensamento crítico.

\section{Conclusões}

Este artigo apresentou uma proposta de currículo e livro didático de computação para o sexto ano do Ensino Fundamental II baseada em conceitos fundamentais da ciência da computação, no domínio de tecnologias e em habilidades de pensamento computacional. Além disso, apresentamos uma experiência preliminar de uso do livro em escola pública e uma discussão em torno de lições aprendidas.

As principais lições aprendidas incluem a necessidade de infraestrutura adequada na escola, as dificuldades na integração da proposta aos currículos atuais, a questão de capacitação do corpo docente, o poder da computação em propiciar experiências interdisciplinares e a perspectiva de mundo que é aberta aos estudantes ao viver esta experiência.

A disseminação do currículo e livro didático propostos ou o seu aproveitamento pela comunidade para melhoria ou inovação curricular pode trazer impactos importantes à educação brasileira. Do ponto de vista curricular, pode acelerar o processo de inclusão da computação nos currículos escolares. Do ponto de vista dos estudantes, cria um espaço de discussão e aprendizagem de tecnologias atuais que coloca-os de frente aos desafios da sociedade contemporânea e com poder de expressão que os torna partícipes ativos do processo de construção do conhecimento e de soluções para os problemas da sociedade.

Em trabalhos futuros, pretendemos avaliar uma experiência integral de aplicação 
do currículo e do livro em um ano escolar completo com turmas do sexto ano.

\section{Agradecimentos}

Este projeto foi apoiado pela FAPESP, através do auxílio de pesquisa 2015/24331-1 e das bolsas de treinamento técnico 2018/12799-7 e 2018/15614-8.

\section{Referências}

Bell, T., Alexander, J., Freeman, I., and Grimley, M. (2009). Computer science unplugged: School students doing real computing without computers. The New Zealand Journal of Applied Computing and Information Technology, 13(1):20-29.

Bell, T., Witten, I. H., and Fellows, M. (1998). Computer Science Unplugged... off-line activities and games for all ages.

Brennan, K. (2013). Learning computing through creating and connecting. Computer, 46(9):52-59.

CIEB (2018). Currículo de Tecnologia e Computação da Educação Infantil ao Ensino Fundamental.

CSTA and ACM (2016). CSTA K-12 Computer Science Standards. The National Academies Press, Washington, DC.

Hazzan, O., Gal-Ezer, J., and Blum, L. (2008). A model for high school computer science education: The four key elements that make it! In Proceedings of the 39th Technical Symposium on Computer Science Education, pages 281-285, New York, NY. ACM.

McNerney, T. S. (2004). From turtles to tangible programming bricks: explorations in physical language design. Personal and Ubiquitous Computing, 8(5):326-337.

Papert, S. and Solomon, C. (1971). Twenty things to do with a computer. Educational Technology Magazine.

Resnick, M., Maloney, J., Monroy-Hernández, A., Rusk, N., Eastmond, E., Brennan, K., Millner, A., Rosenbaum, E., Silver, J., Silverman, B., et al. (2009). Scratch: Programming for all. Communications of the ACM, 52(11):60-67.

Royal Society (2012). Shut down or restart? The way forward for computing in UK schools. The Royal Society, London.

Santos, P. S., Araujo, L. G. J., and Bittencourt, R. A. (2018). A Mapping Study of Computational Thinking and Programming in Brazilian K-12 Education. In 2018 IEEE Frontiers in Education Conference (FIE), pages 1-8. IEEE.

SBC (2017). Referenciais de Formação em Computação: Educação Básica. http://www.sbc.org.br/files/ ComputacaoEducacaoBasica-versaofinal-julho2017.pdf.

Seehorn, D., Carey, S., Fuschetto, B., Lee, I., Moix, D., O’Grady-Cunniff, D., Owens, B. B., Stephenson, C., and Verno, A. (2011). CSTA K-12 Computer Science Standards: Revised 2011. Technical report, CSTA/ACM, New York, NY, USA. 104111.

The College Board (2017). AP Computer Science Principles Course and Exam Description. College Board.

Wing, J. M. (2006). Computational thinking. Communications of the ACM, 49(3):33-35. 